\section{Medïal Seienę}

pISSN 2321-7359; eISSN 2321-7367
Knowledge, attitude and practice towards child abuse among the general population in Saudi Arabia
To Cite:

Saeed MN, Alhasani TM, Al-Ruwaili JMH, Alshaeri NM, Gandurah SF, Alswayed AK, Saad Al-Qahtani KM, Althuwaybi MS, Ali AMB. Knowledge, attitude and practice towards child abuse among the general population in Saudi Arabia. Medical Science, 2022, 26, ms54e1998. doi: https://doi.org/10.54905/disssi/v26i120/ms54e1998

\section{Author Affiliation:}

${ }^{1}$ Consultant of Pediatrics, Prince Sultan Military Hospital, Taif, KSA

${ }^{2}$ Alqunfudah Medical College, Umm Al Qura University, KSA

${ }^{3}$ College of Medicine, Northern Border University, KSA

${ }^{4}$ Alqunfudah Medical College, Umm Al Qura University, KSA

${ }^{5}$ Pediatric resident, Maastricht University, Maastricht, Netherlands

${ }^{6}$ College of Medicine, King Saud bin Abdulaziz University for Health

Sciences, KSA

${ }^{7}$ College of Medicine, King Khalid University, KSA

${ }^{8}$ Collegeof Medicine, Taif University, KSA

${ }^{9}$ Faculty of Medicine, Sohag University, Egypt

\section{Peer-Review History}

Received: 02 December 2021

Reviewed \& Revised: 04/December/2021 to 22/January/2022

Accepted: 24 January 2022

Published: 02 February 2022

\section{Peer-review Method}

External peer-review was done through double-blind method.

URL: https://www.discoveryjournals.org/medicalscience

\section{(c) (i)}

This work is licensed under a Creative Commons Attribution 4.0 International License.

\author{
Muhammad Noman Saeed ${ }^{1}$, Turki Mohammed \\ Alhasani², Jawaher Mohammed Hassan Al-Ruwaili ${ }^{3}$, \\ Naif Mousa Alshaeri" ${ }^{4}$ Saad Fareed Gandurah ${ }^{5}$, \\ Abdulmohsen Khalid Alswayed, ${ }^{6}$ Khalid Mohammed \\ Saad Al-Qahtani ${ }^{7}$, Maha Safar Althuwaybi ${ }^{8}$, Abdalla \\ Mohamed Bakr Ali ${ }^{9}$
}

\begin{abstract}
Background: Child abuse encompasses a wide range of physical, emotional, and sexual abuse, as well as negligence in child care, all of which can have a severe impact on a child's health and development. The purpose of this study is to assess the population's knowledge, attitudes, and behaviours about child abuse in Saudi Arabia. Methodology: This is a cross-sectional study conducted in Saudi Arabia between July and August 2021. This study covers the general population of Saudi Arabia. Online self-completed questionnaires are distributed on social media. The questionnaire has been revised and translated. The questionnaire consists of 16 questions/questions to evaluate knowledge (8), attitude (3), and practice (5) in addition to sociodemographic data. Scores are analysed according to a normal distribution. Results: Our study included 499 individuals, $33.1 \%$ of whom were between the ages of 18 and 25 , and $45.3 \%$ of whom were female. Knowledge, attitude, and practise mean (SD) scores were $71.9 \pm 28.1,46.8 \pm 34.8$ and $70.1 \pm 34.8$, respectively. Knowledge, attitudes, and practice are all associated with age ( $\mathrm{P}$ $=0.050)$. Knowledge $(P=0.001)$ and practice $(P=0.000)$ were both significantly related to marital status. Knowledge and practice are strongly associated with having children $(\mathrm{P}=0.000)$. Conclusion: Attitudes of the Saudi Arabian population towards child abuse were low relative to knowledge and practices. To reduce the incidence of child abuse in society, more efforts are needed to improve knowledge, attitudes and practices about child abuse.
\end{abstract}

Keywords: Child abuse; KAP; Saudi Arabia; Psychiatry

\section{BACKGROUND}

The United Nations Convention on the Rights of the Child (UN CRC) (1989) is the world's most widely advocated child rights instrument, defining a child as 
anyone under the age of eighteen. "Member States will take all proper judicial, managerial, social and educational dealings to defend the child from any practice of physical or emotive violence, harm or abuse, neglect or negligent treatment, ill-treatment or abuse, while the child is in the care of one or more parentages, lawful guardian(s) or additional person with custody of the child (UN CRC, 1989; UN CRC, 2011). Childhood and adolescence are distinct stages in a person's life when their personality is created. Adult mental health is heavily influenced by the quality of education and living at this time. As a result, family and community support are essential for a smooth transition (May-Chahal \& Cawson, 2005; Brown et al., 2019). Child abuse includes a variety of physical, emotional, sexual, and neglect abuses that can have a negative impact on a child's health and development. Physical or mental harm, physical abuse, sexual abuse, misbehaving or neglecting the child, and death of the child are all examples of child abuse (WHO, 2010).

Child abuse can lead to family and social pillars being unstable and frail. The most serious consequence of child abuse is child death. Other repercussions can be found in both childhood and adulthood (Sahebihagh et al., 2017). Several problems, including anxiety, depression, panic disorder, alcoholism, conduct disorder, post-traumatic stress disorder, separation anxiety, and suicidal behavior, are more common among these children, according to studies (Mohammadi et al., 2014). Furthermore, these children are likely to abuse their parents in the future (Naderpoor \& Zare Shahabadi, 2015). Abuse causes low self-esteem, as well as issues with language development and academic achievement (Nourazar et al., 2014).

Stress from child maltreatment can produce changes in the brain, cardiovascular, and immunological systems, as well as metabolism. Child maltreatment causes youngsters to develop undesirable personality traits and engage in risky actions (Eija et al., 2014). Treatment expenditures, prolonged hospitalization, and mental health costs, in addition to the physical, psychological, and social repercussions of child abuse, place a significant financial burden on the family and society (Ghezelseflo \& Rostami, 2015). Inexplicable bruising, markings or injuries on any body area, many unexplained bruises, cigarette burn marks, shattered bones, and scalds, with upward splash marks, are all outward symptoms of abuse. Physical abuse can patent himself in numerous ways, comprising changes in behavior. The symptoms can include a child's fear of authorities approaching their parents for an explanation, aggressive behavior or severe temper tantrums, flinching when touched, despair, and withdrawn behaviour (Ward et al., 2013).

Physical abuse shows visible evidence, whereas mental abuse or neglect does not, but can leave severe, long-lasting scars on the victim's mind. Abused children have a better chance of recovering and healing if they seek help early (Kudagammana, 2011). From the standpoint of children, families, and the entire community in Saudi Arabia and around the world, primary prevention of child abuse is the most critical issue. This study aims mainly to measure the knowledge, attitude, and practice of the general population towards child abuse in Saudi Arabia.

\section{Objectives}

Estimate the level of knowledge, attitude and awareness of the Saudi general population towards child abuse. Find the factors associated with good knowledge, positive attitude and positive practice.

\section{METHODOLOGY}

\section{Study design}

This is a cross-sectional study thatwas conducted between July and August 2021.

\section{Study population and sampling}

The study included the Saudi general population. A simple sampling approach was adopted in this experiment. The EpiTools epidemiology calculator was used to estimate the sample size. (Available at: http://epitools.ausvet.com.au/content.php? page=1ProportionandProportion).

\section{Data collection tools}

An online self-administrated questionnaire was distributed on social media platforms, including Facebook and Twitter. The questionnaire is adapted from Badakar et al., (2020). The adapted questionnaire was translated into Arabic by experts and reviewed and agreed upon by the consultant and the research team. There were 16 questions/statements to assess knowledge (8), attitude (3), and practice (5), in addition to socio-demographic data. Respondents filled out their general information, such as gender, occupation, education, age, and marital status, in the first segment of the questionnaire. The second section of the questionnaire inquireed about the respondent's knowledge of Child Abuse And Neglect (CAN). The third section included questions about how 
people feel about CAN. Questions dealing with the practice of identifying and reporting abuse constituted the fourth section of the questionnaire.

\section{Scoring system}

A correct or positive response received a score of 1 , whereas an incorrect or negative response received a score of 0 . The total score for each section (knowledge, attitude, and practice) were summed and presented as a percentage.

\section{Statistical analysis}

The data was scrutinisedby means of IBM SPSS type 26. A P-value of less than 0.05 was considered significant. Numbers and percentages were used to presentall categorical variables. We used the chi-square test to evaluate risk factors between categorical variables, and the Kruskal-Wallis and Mann-Whitney $U$ tests were used with paranormally distributed continuous variables. A pvalue of less than 0.05 was regarded as statistically significant.

\section{Ethical considerations}

The questionnaire started with a brief explanation of its objective and intent and a reminder to participants that their participation is voluntary. The surveys did not collect names nor collected dates of birth or addresses. All responses were be kept private and safe. Ethical approval was obtained from Taif Research and Studies Department in the Directorate of Health Affairs (IRB Registration No. with KACST, KSA: HAP-02-T-067, approval number: 583).

\section{RESULTS}

Table 1 shows the socio-demographic characters of participants and their Source of information on child abuse. Our results showed that of the 499 participants, 165 (33.1\%) of the participants' ages ranged from 18-25 years old, 168 (33.7\%) aged from 26-35 years old, $96(19.2 \%)$ aged from 36-45 years old, and 70 (14\%) aged 46 and above. $226(45.3 \%)$ of the contributors were women. Regarding the marital state, 170 (34.1\%) were single, and 245 (49.1\%) were married. 293 (58.7\%) of the participants had children, and 145 (48.8\%) of them had 1-3 children. Saudi participants were 455 (91.2\%). Going to the region of residency in KSA, 117 (23.4\%) lived in the central region, $61(12.2 \%)$ lived in the eastern region, and $48(9.6 \%)$ lived in the northern region. Bedouins were $42(8.4 \%)$ of the participants, 126 (25.3\%) lived in rural areas, and 331 (66.3\%) lived in urban areas. Regarding the education level, 335 (67.1\%) had a university degree or more, 125 (25.1\%) had secondary education, and $22(4.4 \%)$ had intermediate education. 186 (37.3\%) of the participants lived in an apartment, while 313 (62.7\%) lived in a house. $253(50.7 \%)$ of the participants had more than five people living in their place. Concerning field of occupation, 67 (13.4\%) worked in military field, 91 (18.2\%) in education, 120 (24\%) in healthcare system, 25 (5\%) in IT \& communications, 47 (9.4\%) in business, 44 (8.8\%) free work, and 91 (18.2\%) not occupied. The source of information on child abuse varied, as $57(11.4 \%)$ of the participants had their information from family and friends, 31 (6.2\%) from journals and newspapers, 240 (48.1\%) from social media, and 171 (34.3\%) had no specific source.

Table 1 Socio-demographic characters of participants $(n=499)$.

\begin{tabular}{|l|l|l|}
\hline Parameter & $18-$ & Frequency (\%) \\
\cline { 2 - 3 } Age, y & $26-$ & $165(33.1 \%)$ \\
\cline { 2 - 3 } & $36-$ & $168(33.7 \%)$ \\
\cline { 2 - 3 } & $46-$ & $96(19.2 \%)$ \\
\hline \multirow{4}{*}{ Sex } & Female & $70(14 \%)$ \\
\hline \multirow{4}{*}{ Marital state } & Male & $226(45.3 \%)$ \\
\hline \multirow{3}{*}{ Do you have children? } & Single & $273(54.7 \%)$ \\
\cline { 2 - 3 } & Married & $170(34.1 \%)$ \\
\cline { 2 - 3 } & Divorced & $245(49.1 \%)$ \\
\cline { 2 - 3 } & Widowed & $58(11.6 \%)$ \\
\hline \multirow{2}{*}{ If yes, how many? } & No & $26(5.2 \%)$ \\
\cline { 2 - 3 } & Yes & $206(41.3 \%)$ \\
\hline
\end{tabular}




\begin{tabular}{|c|c|c|}
\hline \multirow{2}{*}{ Nationality } & Non-Saudi & $44(8.8 \%)$ \\
\hline & Saudi & $455(91.2 \%)$ \\
\hline \multirow{5}{*}{ Region of residency in KSA } & Central Region & $117(23.4 \%)$ \\
\hline & Eastern Region & $61(12.2 \%)$ \\
\hline & Northern Region & $48(9.6 \%)$ \\
\hline & Southern Region & $151(30.3 \%)$ \\
\hline & Western Region & $122(24.4 \%)$ \\
\hline \multirow{3}{*}{ Type of residency } & Bedouin & $42(8.4 \%)$ \\
\hline & Rural & $126(25.3 \%)$ \\
\hline & Urban & $331(66.3 \%)$ \\
\hline \multirow{5}{*}{ Educational level } & Illiterate & $5(1 \%)$ \\
\hline & Primary education & $12(2.4 \%)$ \\
\hline & $\begin{array}{l}\text { Intermediate } \\
\text { education }\end{array}$ & $22(4.4 \%)$ \\
\hline & $\begin{array}{l}\text { Secondary } \\
\text { education }\end{array}$ & $125(25.1 \%)$ \\
\hline & University or more & $335(67.1 \%)$ \\
\hline \multirow{2}{*}{ Accommodation } & 1Apartment & $186(37.3 \%)$ \\
\hline & 2House & $313(62.7 \%)$ \\
\hline \multirow{2}{*}{$\begin{array}{l}\text { Number of people living in } \\
\text { the house }\end{array}$} & 1 to 5 & $246(49.3 \%)$ \\
\hline & More than 5 & $253(50.7 \%)$ \\
\hline \multirow{8}{*}{ Field of occupation } & Military & $67(13.4 \%)$ \\
\hline & Education & $91(18.2 \%)$ \\
\hline & Healthcare system & $120(24 \%)$ \\
\hline & IT\&Communication & $25(5 \%)$ \\
\hline & Business & $47(9.4 \%)$ \\
\hline & Free work & $44(8.8 \%)$ \\
\hline & Others & $14(2.8 \%)$ \\
\hline & Not occupied & $91(18.2 \%)$ \\
\hline \multirow{4}{*}{$\begin{array}{l}\text { Source of information on } \\
\text { child abuse }\end{array}$} & Familyand friends & $57(11.4 \%)$ \\
\hline & $\begin{array}{l}\text { Journals and } \\
\text { newspapers }\end{array}$ & $31(6.2 \%)$ \\
\hline & Social media & $240(48.1 \%)$ \\
\hline & No specific source & $171(34.3 \%)$ \\
\hline
\end{tabular}

Table 2 shows the knowledge of participants on Child Abuse and Neglect. According to knowledge, 422 (84.6\%) knew what CAN are, 26 (5.2\%) were not certain, and 51 (10.2\%) did not know. 399 (80\%) knew the dissimilarity amongst child abuse and child neglect, and 29 (5.8\%) were not certain, 88.2\% think that children have rights regarding CAN, and 4.2\% were not certain, $67.5 \%$ agreed that accusation should be addressed if a child stated that an adult had caused harm and $18.2 \%$ were not certain, $62.7 \%$ agree that children who have been abused usually tell someone soon after the abuse and $17 \%$ were not certain, $81.6 \%$ think that a child with bad hygiene shows that the child is neglected and $8.8 \%$ were not certain, $80 \%$ believe that not having the child's vaccines done or having them done late is a sign of neglect, and $10.4 \%$ were not certain, $31.1 \%$ knew the helpline number for the child in distress in Saudi Arabia, and $50.7 \%$ did not, and the knowledge score obtained from out gathered results is $71.9 \pm 28.1$.

Table 2 Knowledge of participants on Child Abuse and Neglect (CAN)(n=499).

\begin{tabular}{|l|l|l|l|}
\hline Knowledge item & Yes & Not certain & No \\
\hline Do you know what is CAN? & $422(84.6 \%)$ & $26(5.2 \%)$ & $51(10.2 \%)$ \\
\hline $\begin{array}{l}\text { Do you know the difference between child abuse and child } \\
\text { neglect? }\end{array}$ & $399(80 \%)$ & $29(5.8 \%)$ & $71(14.2 \%)$ \\
\hline
\end{tabular}




\begin{tabular}{|l|l|l|l|}
\hline Do you think children have rights regarding CAN? & $440(88.2 \%)$ & $21(4.2 \%)$ & $38(7.6 \%)$ \\
\hline $\begin{array}{l}\text { If the child readily states that adult has caused harm, } \\
\text { accusation should be addressed? }\end{array}$ & $337(67.5 \%)$ & $91(18.2 \%)$ & $71(14.2 \%)$ \\
\hline $\begin{array}{l}\text { Children who have been abused usually tell someone soon } \\
\text { after the abuse? }\end{array}$ & $313(62.7 \%)$ & $85(17 \%)$ & $101(20.2 \%)$ \\
\hline A child with bad hygiene shows that the child is neglected? & $407(81.6 \%)$ & $44(8.8 \%)$ & $48(9.6 \%)$ \\
\hline $\begin{array}{l}\text { Not having the child's vaccines done or having them done } \\
\text { late is a sign of neglect? }\end{array}$ & $399(80 \%)$ & $52(10.4 \%)$ & $48(9.6 \%)$ \\
\hline $\begin{array}{l}\text { Do you know the helpline number for child in distress in } \\
\text { Saudi Arabia? }\end{array}$ & $155(31.1 \%)$ & $91(18.2 \%)$ & $253(50.7 \%)$ \\
\hline Knowledge score (Mean \pm SD) & $71.9 \pm 28.1$ & & \\
\hline
\end{tabular}

Table 3 shows the results according to attitude item showed the following: $65.7 \%$ are aware of the different types of CAN, $11.2 \%$ were not certain, and $23 \%$ are not aware, $48.3 \%$ are aware of the child protection act, and $13.4 \%$ are not certain, $26.3 \%$ have heard of the UNICEF Convention on the rights of the child, and $12.6 \%$ are not certain, and the attitude score (Mean \pm SD) is $46.8 \pm 34.8$. Table 4 presents the practice items, $61.9 \%$ have come across a case of CAN, $7.4 \%$ are not certain, and $30.7 \%$ did not come across any case (Figure 1), 56.1\% have tried to help a victim of CAN and $6.6 \%$ are not certain, $74.5 \%$ will report a case of CAN, and $18 \%$ are not certain, $79 \%$ are able to inform the concerned people if the child is abused and $14.6 \%$ are not certain, $78.8 \%$ will take steps to find out the truth if they feel a child might be a victim of CAN and $14.8 \%$ are not certain (Figure 2), and the practice score (Mean \pm SD) is $70.1 \pm 34.8$.

Table 3 Attitude of participants towards Child Abuse and Neglect (CAN)(n=499).

\begin{tabular}{|l|l|l|l|}
\hline Attitude item & Yes & Not certain & No \\
\hline Are you aware of the different types of CAN? & $328(65.7 \%)$ & $56(11.2 \%)$ & $115(23 \%)$ \\
\hline Are you aware of the child protection act? & $241(48.3 \%)$ & $67(13.4 \%)$ & $191(38.3 \%)$ \\
\hline $\begin{array}{l}\text { Have you heard of the UNICEF Convention on the } \\
\text { rights of the child? }\end{array}$ & $131(26.3 \%)$ & $63(12.6 \%)$ & $305(61.1 \%)$ \\
\hline Attitude score (Mean \pm SD) & $46.8 \pm 34.8$ & & \multicolumn{2}{|l|}{} \\
\hline
\end{tabular}

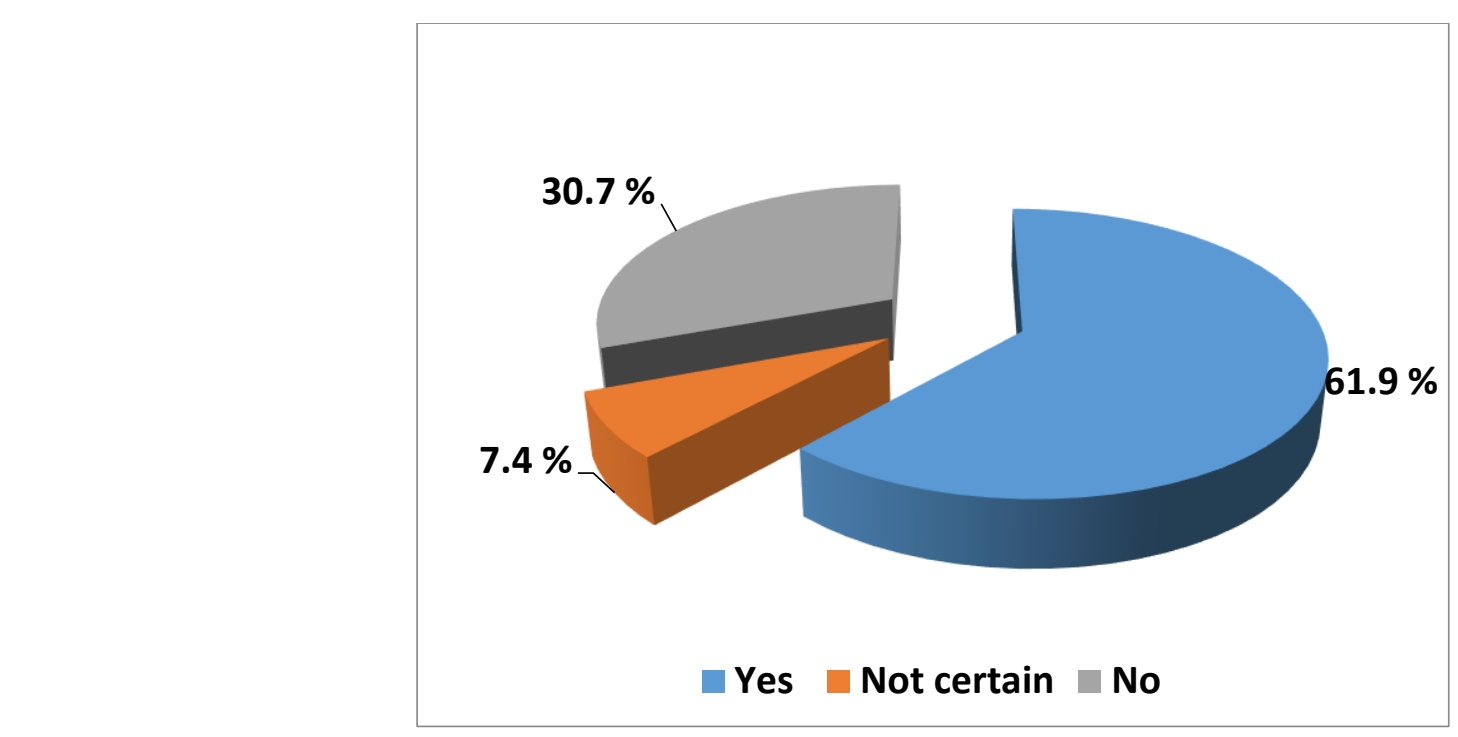

Figure 1 Participant come across a case of CAN 
Table 4 Practice of participants towards Child Abuse and Neglect (CAN)(n=499).

\begin{tabular}{|l|l|l|l|}
\hline Practice item & Yes & Not certain & No \\
\hline Have you come across a case of CAN? & $309(61.9 \%)$ & $37(7.4 \%)$ & $153(30.7 \%)$ \\
\hline Have you ever tried to help a victim of CAN? & $280(56.1 \%)$ & $33(6.6 \%)$ & $186(37.3 \%)$ \\
\hline Will you report a case of CAN? & $372(74.5 \%)$ & $90(18 \%)$ & $37(7.4 \%)$ \\
\hline Are you able to inform the concerned people if the child is abused? & $394(79 \%)$ & $73(14.6 \%)$ & $32(6.4 \%)$ \\
\hline $\begin{array}{l}\text { If you feel a child might be a victim of CAN, will you take any steps to } \\
\text { find out the truth? }\end{array}$ & $393(78.8 \%)$ & $74(14.8 \%)$ & $32(6.4 \%)$ \\
\hline Practice score (Mean \pm SD) & $70.1 \pm 34.8$ & \\
\hline
\end{tabular}

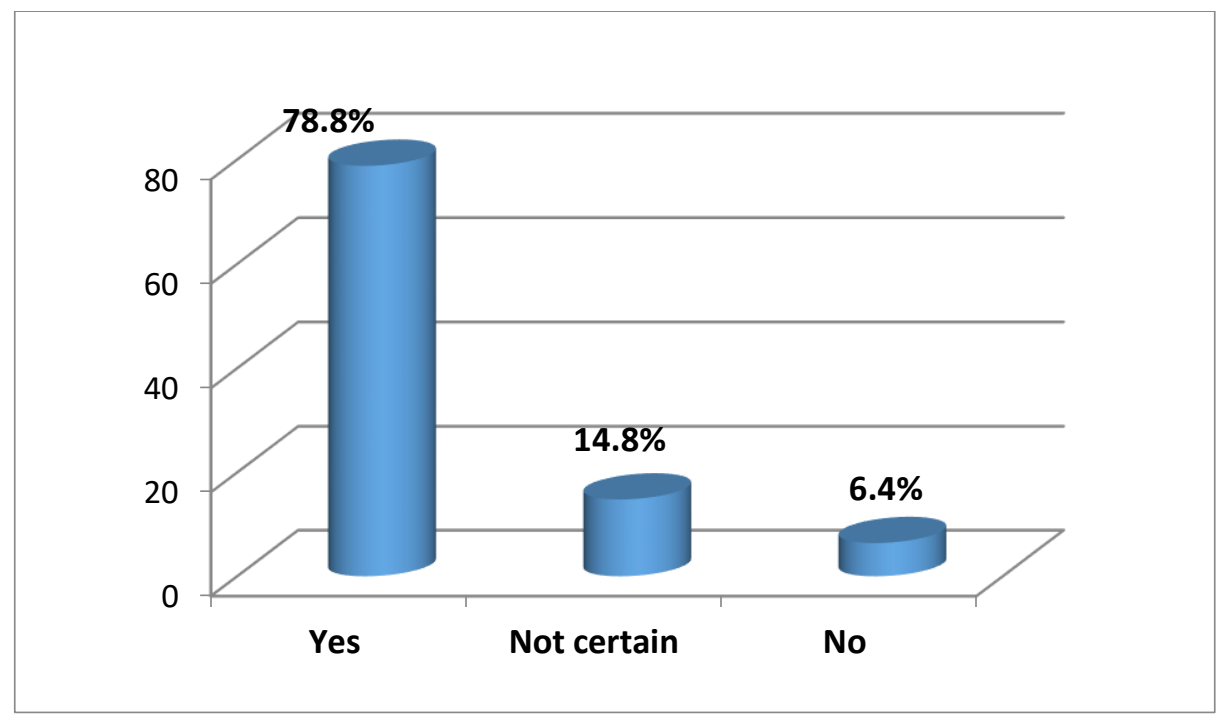

Figure 2 The participant feel a child might be a victim of CAN, will you take any steps to find out the truth

Table 5 illustrates the association between socio-demographic characters and knowledge, attitude, and practice scores. Age parameter is associated significantly with knowledge $(\mathrm{P}=0.007)$, with attitude $(\mathrm{P}=0.040)$, and with practice $(\mathrm{P}=0.000)$. The marital state is associated significantly with knowledge $(\mathrm{P}=0.001)$ and practice $(\mathrm{P}=0.000)$. Having children is associated significantly with knowledge and practice $(\mathrm{P}=0.000)$. Education level is associated significantly only with practice $(\mathrm{P}=0.001)$, while the field of occupation is associated significantly with knowledge and attitude $(\mathrm{P}=0.001)$ and practice $(\mathrm{P}=0.000)$, and source of information is associated significantly with knowledge only $(\mathrm{P}=0.001)$.

Table 5 Association between socio-demographic characters and knowledge, attitude, and practice scores ( $\mathrm{n}=499)$.

\begin{tabular}{|c|c|c|c|c|c|c|c|}
\hline \multicolumn{2}{|l|}{ Parameter } & $\begin{array}{l}\text { Knowledge } \\
\text { score }\end{array}$ & P-value ${ }^{*}$ & $\begin{array}{l}\text { Attitude } \\
\text { score }\end{array}$ & P-value ${ }^{*}$ & $\begin{array}{l}\text { Practice } \\
\text { score }\end{array}$ & P-value* \\
\hline \multirow{4}{*}{ Age, $y$} & $18-$ & $68.5 \pm 26.1$ & \multirow{4}{*}{0.007} & $41.3 \pm 35.5$ & \multirow{4}{*}{0.040} & $62.5 \pm 35$ & \multirow{4}{*}{0.000} \\
\hline & $26-$ & $73 \pm 30.1$ & & $51 \pm 34.3$ & & $72.4 \pm 34.4$ & \\
\hline & $36-$ & $75.2 \pm 27.9$ & & $50.7 \pm 34.6$ & & $73 \pm 36.5$ & \\
\hline & $46-$ & $73.4 \pm 27.9$ & & $44.3 \pm 33.5$ & & $78.6 \pm 30.2$ & \\
\hline \multirow{2}{*}{ Sex } & Female & $74.4 \pm 23.6$ & \multirow{2}{*}{0.912} & $48.3 \pm 35.2$ & \multirow{2}{*}{0.417} & $68.4 \pm 33.6$ & \multirow{2}{*}{0.120} \\
\hline & Male & $70 \pm 31.3$ & & $45.6 \pm 34.5$ & & $71.5 \pm 35.8$ & \\
\hline \multirow{4}{*}{ Marital state } & Single & $72.3 \pm 22.3$ & \multirow{4}{*}{0.001} & $45.3 \pm 35.7$ & \multirow{4}{*}{0.836} & $64.4 \pm 33.7$ & \multirow{4}{*}{0.000} \\
\hline & Married & $69.1 \pm 31.3$ & & $47 \pm 35.2$ & & $70.1 \pm 35.5$ & \\
\hline & Divorced & $78.9 \pm 28.5$ & & $49.5 \pm 30.8$ & & $81.4 \pm 33.1$ & \\
\hline & Widowed & $81.3 \pm 26.1$ & & $48.8 \pm 35.6$ & & $82.4 \pm 32.2$ & \\
\hline \multirow{2}{*}{$\begin{array}{l}\text { Do you have } \\
\text { children? }\end{array}$} & No & $68.9 \pm 25.9$ & \multirow{2}{*}{0.000} & $44.2 \pm 36.4$ & \multirow{2}{*}{0.141} & $62.7 \pm 35$ & \multirow{2}{*}{0.000} \\
\hline & Yes & $74.1 \pm 29.4$ & & $48.6 \pm 33.6$ & & $75.3 \pm 33.8$ & \\
\hline
\end{tabular}




\begin{tabular}{|c|c|c|c|c|c|c|c|}
\hline \multirow{2}{*}{ If yes, how many? } & 1 to 3 & $73.2 \pm 29.7$ & \multirow{2}{*}{0.722} & $49.7 \pm 36.1$ & \multirow{2}{*}{0.526} & $73.3 \pm 34$ & \multirow{2}{*}{0.124} \\
\hline & More than 3 & $74.1 \pm 29.7$ & & $47.2 \pm 32$ & & $77.2 \pm 33.9$ & \\
\hline \multirow{2}{*}{ Nationality } & Non-Saudi & $73.3 \pm 33.6$ & \multirow{2}{*}{0.164} & $46.3 \pm 33.9$ & \multirow{2}{*}{0.949} & $71.4 \pm 36$ & \multirow{2}{*}{0.702} \\
\hline & Saudi & $71.9 \pm 27.6$ & & $46.9 \pm 34.9$ & & $70 \pm 34.8$ & \\
\hline \multirow{5}{*}{$\begin{array}{l}\text { Region of residency } \\
\text { in KSA }\end{array}$} & Central Region & $69.7 \pm 29.7$ & \multirow{5}{*}{0.216} & $44.2 \pm 34.2$ & \multirow{5}{*}{0.754} & $74.7 \pm 32.3$ & \multirow{5}{*}{0.000} \\
\hline & Eastern Region & $70.7 \pm 32.8$ & & $45.4 \pm 31.1$ & & $71.5 \pm 41.6$ & \\
\hline & Northern Region & $77.6 \pm 28.5$ & & $52.1 \pm 33.7$ & & $82.5 \pm 29.4$ & \\
\hline & Southern Region & $72.1 \pm 27.5$ & & $47.1 \pm 37$ & & $63.9 \pm 34.5$ & \\
\hline & Western Region & $72.5 \pm 24.6$ & & $47.6 \pm 35.1$ & & $67.7 \pm 34.5$ & \\
\hline \multirow{3}{*}{ Type of residency } & Bedouin & $78.3 \pm 28.6$ & \multirow{3}{*}{0.001} & $52.4 \pm 26.7$ & \multirow{3}{*}{0.030} & $91 \pm 24.3$ & \multirow{3}{*}{0.000} \\
\hline & Rural & $66.3 \pm 27.7$ & & $40 \pm 33.5$ & & $58.5 \pm 38.5$ & \\
\hline & Urban & $73.3 \pm 28$ & & $48.7 \pm 35.9$ & & $71.9 \pm 32.9$ & \\
\hline \multirow{5}{*}{ Educational level } & Illiterate & $45 \pm 31.4$ & \multirow{5}{*}{0.146} & $26.7 \pm 27.9$ & \multirow{5}{*}{0.290} & $40 \pm 28.3$ & \multirow{5}{*}{0.001} \\
\hline & Primary education & $59.4 \pm 42.7$ & & $38.9 \pm 27.9$ & & $60 \pm 49.8$ & \\
\hline & $\begin{array}{l}\text { Intermediate } \\
\text { education }\end{array}$ & $73.3 \pm 26.9$ & & $50 \pm 32.2$ & & $79.1 \pm 31.2$ & \\
\hline & $\begin{array}{l}\text { Secondary } \\
\text { education }\end{array}$ & $74.3 \pm 27.3$ & & $42.7 \pm 34.1$ & & $78.1 \pm 31.8$ & \\
\hline & University or more & $71.9 \pm 27.7$ & & $48.7 \pm 35.5$ & & $67.3 \pm 35$ & \\
\hline \multirow{2}{*}{ Accommodation } & 1Apartment & $69.7 \pm 32.9$ & \multirow{2}{*}{0.794} & $48.6 \pm 35.4$ & \multirow{2}{*}{0.340} & $72.2 \pm 35.8$ & \multirow{2}{*}{0.092} \\
\hline & 2House & $73.3 \pm 24.8$ & & $45.7 \pm 34.5$ & & $68.9 \pm 34.3$ & \\
\hline \multirow{2}{*}{$\begin{array}{l}\text { Number of people } \\
\text { living in the house }\end{array}$} & 1 to 5 & $68.9 \pm 30.9$ & \multirow{2}{*}{0.108} & $46 \pm 36.9$ & \multirow{2}{*}{0.554} & $67.4 \pm 36.9$ & \multirow{2}{*}{0.186} \\
\hline & More than 5 & $74.9 \pm 24.8$ & & $47.6 \pm 32.7$ & & $72.8 \pm 32.5$ & \\
\hline \multirow{8}{*}{ Field of occupation } & Military & $72.2 \pm 32.2$ & & $38.4 \pm 33$ & & $73.5 \pm 34.9$ & \\
\hline & Education & $73.3 \pm 27.1$ & & $49.5 \pm 36$ & & $69.5 \pm 36.1$ & \\
\hline & Healthcare system & $73.8 \pm 26.7$ & & $55.9 \pm 33.8$ & & $73.5 \pm 32.1$ & \\
\hline & IT\&Communication & $77.5 \pm 32.1$ & $\mid$ & $53.4 \pm 27.3$ & م001 & $83.2 \pm 28.1$ & م \\
\hline & Business & $74.5 \pm 29.3$ & 0.001 & $50.4 \pm 31$ & 0.001 & $79.2 \pm 33.4$ & 0.000 \\
\hline & Free work & $75.3 \pm 28.9$ & & $47 \pm 35.5$ & & $73.7 \pm 38.3$ & \\
\hline & Others & $59.9 \pm 35.1$ & & $42.9 \pm 44.2$ & & $55.8 \pm 40.9$ & \\
\hline & Not occupied & $65.6 \pm 23.7$ & & $35.2 \pm 34.6$ & & $55.9 \pm 32.6$ & \\
\hline & Familyand friends & $60.6 \pm 34$ & & $36.9 \pm 33.2$ & & $66.7 \pm 36.6$ & \\
\hline $\begin{array}{l}\text { Source of } \\
\text { information on }\end{array}$ & $\begin{array}{l}\text { Journals and } \\
\text { newspapers }\end{array}$ & $52.9 \pm 39.3$ & 0.001 & $48.4 \pm 41.2$ & 0.125 & $68.4 \pm 34.6$ & 0.368 \\
\hline child abuse & Social media & $75.9 \pm 25$ & & $48.8 \pm 33.7$ & & $68.5 \pm 35.4$ & \\
\hline & No specific source & $73.7 \pm 25.5$ & & $47 \pm 35.4$ & & $73.7 \pm 33.4$ & \\
\hline
\end{tabular}

*Kruskal-Wallis and Mann-Whitney tests were used.

\section{DISCUSSION}

Any vision for a country's prosperity and development is contingent on the wellbeing and security of its children. When a child is subjected to CAN at a young age, it disrupts their sense of self and their ability to form healthy relationships with others by leaving long-term emotional and psychological scars (Saxena et al., 2015; Alshouimi et al., 2021). Children require tender affection, understanding, and care from family members at all phases of their childhood. When compared to their nonabused peers, physically abused youngsters have been found to be more despised and unpopular. They also showed less intimacy, more conflict, and more negative effects with close friends than nonabused youngsters do with friends (Koizumi \& Takagishi, 2014).

A descriptive study was held on King Abdulaziz University Hospital, a tertiary care teaching hospital in western Saudi Arabia, to measure the knowledge, insight, and specialized knowledge of paediatricians regarding CAN (Habib, 2012). The findings of this work demonstrated that the total score of knowledge of child abuse was 88.0 (4.4) and the score of knowledge of child neglect was 89.2 (2.3); the scores were adequate compared to our knowledge score results which are $71.9 \pm 28.1$. No great controversy was seen 
regarding the knowledge of the participants, as the majority knew what is CAN, while the minority either did not know or were uncertain. This may be explained by the reported knowledge score, but some items resulted in lowering the score of knowledge, as knowing the helpline number for the child in distress in Saudi Arabia, only 31.1\% of the participants knew the number.

A cross-sectional study of participants at the $12^{\text {th }}$ Pediatric Dentist Conference in Iran found that participants' average knowledge, attitudes and practices regarding child abuse were $10.24 \pm 2.68$ and $41.54 \pm 11.24$ and 2.78 \pm 1.05 , respectively. Comparing those results to ours, we see a great difference in the scores as the knowledge score in our study is $71.9 \pm 28.1$, attitude score is $46.8 \pm 34.8$, and practice score 70.1 \pm 34.8 . Garrousi et al., (2006) investigated the knowledge and attitudes of general practitioners (GPs) in connection to child abuse and found that 55\% of GPs had insufficient information about the early finding of child abuse cases, which is different from the findings of the existing study. The current study's knowledge scores are higher than those reported in earlier research from other nations (John et al., 1999; Al-Habsi et al., 2009).

\section{CONCLUSION}

With the goal of minimising child abuse in the community, extra efforts must be made to enhance knowledge, attitude, and practice about child abuse. To achieve this goal, a specific course on the identification of different signs of child abuse, the importance of identifying cases of physical and psychological child abuse, how to report different cases, how to take a history of abuses. Additionally, continuing education programmes and conferences should be used to educate the public, parents, and even healthcare workers.

\section{Funding}

The study did not receive any external funding.

\section{Conflict of interests}

The authors declare that there are no conflicts of interests.

Data and materials availability

All data associated with this study are present in the paper.

\section{REFERENCES AND NOTES}

1. Al-Habsi SA, Roberts GJ, Attari N, Parekh S. A survey of attitudes, knowledge and practice of dentists in London towards child protection. Are children receiving dental treatment at the Eastman Dental Hospital likely to be on the child protection register? Br Dent J 2009; 206: 1-5.

2. Alshouimi OA, Almusaad MN, Aldawood MM, Khalaf AM, Almhizai RA. Medical students' knowledge of child abuse and neglect in Saudi Arabia: A cross-sectional study. Medical Science 2021, 25(114), 1844-1850

3. Badakar C, Gowtham A, Hugar SM, Gokhale NS, Davalbhakta R, Shah S. Knowledge, attitude, and practices regarding CAN among members of different occupations in belagavi: A questionnaire study. Int J Pedod Rehabil 2020; 5(1):7-9.

4. Brown ECB, Garrison MM, Bao H, Qu P, Jenny C, RowhaniRahbar A. Assessment of Rates of Child Maltreatment in States With Medicaid Expansion vs States Without Medicaid Expansion. JAMA Netw Open 2019; 2(6):e195529. doi: 10.1001/jamanetworkopen.2019.5529.

5. Eija P, Mika H, Aune F, Leila L. How public health nurses identify and intervene in child maltreatment based on the national clinical guideline. Nurs Res Pract 2014; 2014:425460. doi: 10.1155/2014/425460.

6. Garrousi B, Safizadeh H, Bahramnejad B. Knowledge, attitude and practice of general practitioners in Kerman concerning child abuse. Payesh Health Monit 2006; 5: 213 220.

7. Ghezelseflo M, Rostami M. Relationship of child abuse with personality features and high risk behaviors in adolescents. J Kerman Univ Medical Sci 2015; 19(2).

8. Habib HS. Pediatrician knowledge, perception, and experience on child abuse and neglect in Saudi Arabia. Ann Saudi Med 2012; 32(3):236-42. doi: 10.5144/0256-4947.2012 .236 .

9. John V, Messer LB, Arora R, Fung S, Hatzis E, Nguyen T, San A, Thomas K. Child abuse and dentistry: a study of knowledge and attitudes among dentists in Victoria, Australia. Aust Dent J 1999; 44(4):259-67. doi: 10.1111/j.18347819.1999.tb00230.x.

10. Koizumi M, Takagishi H. The relationship between child maltreatment and emotion recognition. PLoS One 2014; 9(1):e86093. doi: 10.1371/journal.pone.0086093. 
11. Kudagammana ST. Defining and comprehending child abuse at present times. An appraisal. Sri Lanka J Forensic Med Sci Law 2011; 1(2):28-32.

12. May-Chahal C, Cawson P. Measuring child maltreatment in the United Kingdom: a study of the prevalence of child abuse and neglect. Child Abuse Negl 2005; 29(9):969-84. doi: 10.1016/j.chiabu.2004.05.009.

13. Mohammadi MR, Zarafshan H, Khaleghi A. Child Abuse in Iran: a systematic review and meta-analysis. Iran $\mathrm{J}$ Psychiatry 2014; 9(3):118-24.

14. Naderpoor $Y$, ZareShahabadi A. The Relationship between Childhood Violence Experiences And Violence against Women in Koohdasht City. Womens Stud 2015; 12(4):93-118.

15. Nourazar SG, Kakaie MR, Ranjbar F, Sadeghibazargani H, Farahbakhsh M. Prevalence of child abuse in child and adolescent clinical population referred to psychiatric facilities in Tabriz University of Medical Sciences. J Anal Res Clin Med 2014; 2(3), 87-93.

16. Sahebihagh MH PhD, Hosseini SZ Ms, Hosseinzadeh M PhD, Shamshirgaran SM PhD. Knowledge, Attitude and Practice of Community Health Workers Regarding Child Abuse in Tabriz Health Centers in 2015-2016. Int J Community Based Nurs Midwifery 2017; 5(3):264-274.

17. Saxena Y, Nanjundappa YK, Sreedhar S, Reddy C. Assessment of child abuse at ground and grassroot level: A KAP study among Anganwadi workers and auxiliary nurse midwives in Bangalore. Int J Med Sci Public Health 2015; 4:669-73.

18. UN Committee on the Rights of the Child, 56th Session General Comment No.13 (2011) Article 19: The right of the child to freedom from all forms of violence.

19. UN Convention on the Rights of the Child (With Optional Protocols). Available at: http://www.unicef.org/crc. [Accessed 20 June 2021].

20. Ward MG, Ornstein A, Niec A, Murray CL; Canadian Paediatric Society, Child and Youth Maltreatment Section. The medical assessment of bruising in suspected child maltreatment cases: A clinical perspective. Paediatr Child Health 2013; 18(8):433-42. Erratum in: Paediatr Child Health 2013; 18(9):456.

21. World Health Organization. Child maltreatment. Geneva: WHO; 2010. [20 June 2021] Available from: [http://www. who.int/topics/child_abuse/en/]. 